\title{
Aesthetic Expression of Folk Dance Works in Modern Beijing Area
}

\author{
Ningning Wang \\ School of Literature \\ Capital Normal University \\ Beijing, China
}

\begin{abstract}
As one of the major categories of dance art, folk dance is a cultural achievement jointly created by people of all nationalities. It not only accumulates the ancient culture but also inherits the national aesthetic psychology and reflects the regional characteristics and integrates spirit of the time through the performance of the dancers. The aesthetic expression of folk dance in modern Beijing is mainly reflected in the admiration and worship of vitality in the dancing works. At the same time, it combines both the spirit of "Confucianism" and the connotation of "Tao" in traditional culture. In admiration and worship of vitality, the folk dance in modern Beijing mainly presents two kinds of aesthetic features: the praise of the power of body and the worship of life force. The cultural connotation of Confucianism and Taoism is mainly reflected in the cultural appeal of "vulgar beauty" and "fairy beauty".
\end{abstract}

Keywords-modern; Beijing; folk dance works; aesthetic expression

\section{INTRODUCTION}

Dance is a cultural phenomenon, as well as a dynamic image art. The aesthetic expression of dance aims to emphasize the aesthetic tendencies, aesthetic attitudes and aesthetic rules reflected by different types of dance works in a certain era. Folk dance, as a major genre of dance art, is a cultural achievement jointly created by people of all ethnic groups, which not only accumulates ancient culture but also inherits national aesthetic psychology and reflects the geographical characteristics combining with the spirit of the time through the performance of dancers. The aesthetic expression of folk dance is reflected not only in the formal characteristics represented by the dance language but also in the spiritual connotations reflected in the dance works. Looking at the development vein of folk dance in Beijing, most of the folk dances come from the north. Even the folk dance works born in Beijing have extremely strong northern color. Therefore, the aesthetic characteristics of folk dance in Beijing tend to be more open-minded and have the northern cultural characteristics with infinite vitality. In the development, it also takes into consideration the cultural characteristics of the Central Plains Huaxia and Haidai Dongyi. In twentieth century, Beijing experienced setback and turmoil, but the development of folk dance has shown a strong vitality, which is closely related to the folk activities in Beijing such as seasons festival, religious rituals, flower show, good luck, and hitting the Central Plains and so on. It also reflects the vigorous vitality of Beijing culture, and this vitality carries the cultural genes of the Chinese nation for thousands of years. Therefore, the aesthetic tendency manifested in modern folk dance mainly presents as admiration and worship of vitality, and reflects the spirit of "Confucianism" and connotation of "Tao" in traditional culture.

\section{THE ADMIRATION AND WORSHIP OF VITALITY}

When studying the folk dance works in Beijing, it can be found most of the dances are very simple in the arrangement and movement without garish attitude, but are orderly and full of "sense of ritual" and "sense of volume" when organized together. Such "sense of ritual" and "sense of volume" echo the theme expressed by dance and are eventually embodied as a kind of worship of vitality, and it also includes the "noble" aesthetic ideal. Under the influence of this, the folk dance in Beijing mainly shows two kinds of aesthetic features: the praise of the power of the body and the worship of the beauty of life. Among them, the affirmation of the power of the body is mainly manifested in the formal characteristics of dance, including the magnificent momentum pursued by the dance scene scheduling, the simple and rugged beauty pursued by the dance performances, and the worship of the power of life is mainly manifested in the noble thoughts pursued by the content of dance. The folk dance works directly originating from the north in Beijing mainly include bamboo horse, lion dance, dragon dance, and butterfly clubs, catching butterflies and reaching the cloud. These dances often use the form of multiperson dance to perform in the square and apply music, costumes, and props to show the majestic scenes and magnificent momentum. The folk dances including coloredlantern making, object resembling, props and masks performed in festival celebration, religious sacrifices and folk flower show should use multi-person performances and formation changing to present dance content and complete dance narratives. The performance content of "running bamboo horse dance" Shayu Village of Shayu town in Huairou County in Beijing is from the story of "Empress Dowager Xiao Hunting" in the Northern Song Dynasty. The story originated in the Northern Song Dynasty when the war between Song and Liao constantly broke out, and Liao settled in the north of the Great Wall. In the interval of battle, 
master of Liao, Empress Dowager Xiao led Han Chang, Xiao Tianzuo, and Xiao Tianyou goes out hunting for entertainments. In order to simulate the scenes of Empress Dowager Xiao hunting, the dance uses "bamboo horse" (artificial horse made of bamboo chip) to represent the war horses, with eight people riding "horse" and holding whip to make a variety of patterns. It uses wildly beating gongs and drums to exaggerate the atmosphere and manifests the joy after the hunt by using music and singing. In creating momentum, the actors of bamboo horse gradually formed the patterns of "round field", "square dou", "creating incense lore" and "weaving village basketry" through performance way of running round field with the help of instrument accompaniment to express the intense atmosphere of hunting. During the performance, the actors show the ups and downs of moods of Empress Dowager Xiao in hunting through the control of stopping and moving the bamboo horse and create the battle formation of a large number of mounted and foot soldiers in dance through the control of the rhythm of the pace.

Because Beijing is the center of imperial power, folk dancers in Beijing tend to adopt more solemn and dignified dance posture. This attitude is closer to "emotional" dance gestures that express people's emotions. Lion dance is a kind of sacrificial dance, which represents the longing for favorable weather and peaceful life of common people and reflects the most basic desire for survival of human. Lions are often the auspicious incarnation in the hearts of people, holding the desire of eliminating disasters and good luck of the people. Therefore, lion dance is performed on every festive day. The main reason why people choose to use a lion as a prop for dance is that the lion is ferocious and overwhelming. As the king of all beasts, it is fearless. People used to think of lions as auspicious beasts, and feudal ruling class often regards lions as symbols of authority. Tongshan Lion in Dongzhu of Beijing is rewarded by Empress Dowager Cixi in person, meaning "a long life". Here, the lion is the carrier of desire, which is the highest symbol above all else. Lion dance mainly perform the lion's five emotions of joy, anger, sadness, fear, and shock, the dynamic characteristics are often summarized into "the lion first shakes the bell to shape the brave and lively image. It imitate cats and dogs by jumping, moving, licking and scratching, and is good at perform the joy, anger, sadness, fear and shock. The bell rings when it is happy while it pauses or suddenly changes when it is frightened. It shivers and retracts head when it is sad while it shakes to manifest power and prestige when it is angry."[1] Here, the lion becomes the object to which people reflect their own emotional desires, since the change of emotion is directly related to whether the desire is satisfied. In addition to emphasizing the production of lion props, performers of lion dance pay more attention to holding way of props, basic movements and grasp and choice of dance segments, and the coordination between two dancers is also crucial. Therefore, the lion dance represents people's longing for a better life and show the rough and bold dance gesture.

The dances from north such as Butterflies meeting, catching butterflies, dragon dance, and reaching cloud mostly show the things of the nature. These dances are generally performed at festival and temple flower show, of which the functions are representing the joy and sentiment of the people and performing people's admiration to the mysterious power of nature. This admiration is the sublime beauty that the dance content needs to highlight. In the face of the mysterious power of nature, people praise and eulogize through the dance to pray for the shade and love of nature. In the praise of the power of nature, folk dances in Beijing often present noble aesthetic ideals through indirect and direct expression. First of all, in the sacrificial activities, people often directly express their wishes by means of dance. Dragon is a symbol of the strong power of nature. People's worship of the dragon is the worship of the authority represented by the dragon and people can experience the sublime aesthetic feeling intuitively through watching the dragon dance performance. In style, the dragon dance in Beijing emphasizes dignity and majesty, giving people a sense of holiness. "This is inseparable from the worship of the dragon of people in the ancient capital, the superstition of the 'true dragon emperor' and the dragon images referred from the ancient buildings in the capital.[2] The performance routines of Beijing dragon dance are very rich, including representative of the "two dragon out of water", "three circles around the moon", "golden dragon plate jade chopstick", "go toward four directions", "leave the fence", and "double turn" and so on. In the performance, the heroic posture of dragon flying can be shown through the interaction between the dancers who play the dragon ball and those who play the dragon. Dragon dancers apply the movement method of "round field step" under the command of the dancers playing dragon ball to uniformly, orderly, and coherently show the actions of dragon including upturning, backspin, shuttle, winding, conquering the sea and twisting the head, highlighting the dignity and majesty of the dragon in creating momentum. It is precisely because of the visual display of the dragon's image and posture; the audience is unconsciously integrated into the dance and produce noble aesthetic feelings. Second, the noble mission of the power of nature is implied in people's enthusiastic feeling for nature in addition to being intuitively embodied in the role of nature in humans through folk dance. There are a lot of dances that shows the relationship between man and nature in Beijing, and the butterfly meeting is one of them. According to the history of the butterfly meeting, in the early Yuan Dynasty, an eye disease was prevalent in Miyun County in Beijing, and people suffer but are helpless. Later, a tour doctor came here and use butterfly as the raw material to make medicine, which cure the patient's eye disease. Since then, people regard the butterfly as a symbol of good fortune. In order to be able to always get it blessing, people created the butterfly meeting. Butterfly meeting takes performing the posture of butterflies as the main content, which is completed by the young and children together. Among them, young people were divided into two groups: "Legs" and "Shoulder", performing by holding the children carrying butterfly props when walking and playing. When performing the "fly" gesture of butterfly, "legs" and "shoulder" are required to go "round field" step fast and steadily, so as to perform a light and smooth feeling; in the performance of the gesture of 
butterfly's shaking wings, the action is required to be beautiful and risky to highlight the cleverness and smartness of butterfly. In the butterfly meeting, the vivid and joyful scenes where children play the role of butterflies and recreate urchins playing butterflies reflect the warm and exultant festive atmosphere. Butterflies symbolize the gift of nature, while the youth and children show the harmony between man and nature the reproduction of scenes of imitating butterflies, playing butterflies and catching butterflies, so that the sense of sublime is manifested in such gratitude and self-affirmation.

\section{SPIRIT OF "CONFUCIANISM" AND CONNOTATION OF "TAO"}

The spirit of "Confucianism" and connotation "Tao" in Chinese traditional culture are mainly reflected in the pursuit of "vulgar beauty" and the expression of "fairy beauty" in Beijing folk dance. The so-called "vulgar beauty" means "the beauty of longevity" - "This beauty manifests the extremely special understanding of the human body. To the Chinese people, the secular body has divinity and limited life can be infinitely prolonged so as not to die, so longevity has become the beauty most concerned by Chinese, namely vulgar beauty of longevity."[3] Festival activities in Beijing and various temples fair, pilgrim association and other activities have folk song and dance performances, so people can pray for the annual happiness and luckiness in these activities through different types of song and dance performances. The folk dance in Beijing that can embody "vulgar beauty" best is the Yangko, which includes "Stilt Yangko", "ground Yangko", "big class and small class", "catching Butterfly", and "folk songs", etc. All of them has the characteristics of Yangko: Taking Yangko step, twisting waist, shaking knees, and exchange feelings between characters with fun to perform the rich life taste."[4] In these yangko, "stilts yangko" is the most representative one, which also can reflect the ethical character of highlighting secular and affection of Confucian. In the background music of stilts yangko, there are dance works taking birthday celebration as the main theme such as "longevity flower". "According to a folk artist Gao Zhanting, the stilts in Gaojia Lianghe Village in Miaocheng county were learned from Shunyi County in the early Qing Dynasty. In old days, stilts are mainly used to worship God, worship the temple, and pray for grain harvest and luckiness of people and livestock."[5] The ethical rules that are stressed by Confucianism are also fully reflected in stilt performance: "stilt performance has strict rules, paying attention to 'recognize the flag instead of people', which means it is subject to the command of the governor and the braod command pannant of head."[6] Although performers are often subject to the requirement of a variety of complicated rules and programs, the dance effect is not influenced. On the contrary, this solemn and spectacular dance style precisely reflects the respect of people for ancestors and gods as well as the moral norms of "regulating things with righteousness and regulating heart with ceremony" of the Confucian, which better embody humanism's expression of secular beauty.

The Taoists believe that "the soul is immortal as the body of life, so it is true, and in turn the existence of this flesh is false. The 'nature' is true while 'people' is false."[7] The "fairy beauty" of Taoist is actually a kind of seek and interrogation of the life as well as a kind of expectation and aspiration of sensual life for the natural reason, which is the peculiar carefree beauty of ancient China. Therefore, the Taoist emphasize on "eternal life", "quiet and inaction", "back to nature" ... ..., seeking surpassing in the world, finding happiness in pain, and taking things as they are in adversity ... freedom is reflected in the way of "game". There is no repression and suffocation here, and it is light, smart, and elegant. Freedom not only keeps 'longevity', but also enhances the 'life', which cherishes life without being bound, or that the reason why life is worth cherishing is because it can bring relaxed pleasure."[8] The drum and cymbals folk dance in Beijing just demonstrated this unrestrained, happy and lively atmosphere. Drum and cymbals folk dances include "flower cymbal and big drums", "Pan meeting", "Wuchozi", "Taiping Drum", and "big Drum" and so on, which often appear in festival celebration and foil the happy and harmonious atmosphere as the final program. In the form of manifestation, the drum and cymbals folk dance doesn't have rigid regularity requirements on the dance posture and program, so dancers can perform different dance movement under the drums rhythm. The dance cannot do without the drum, and the drum also changes with the dance. This way of performing without restriction and restraint reflects the aesthetic ideal that people enjoy and do their utmost. In the content of performance, drum and cymbals folk dance includes drum sets, music tunes and lyrics. Among them, different drum sets and music tunes in the performance can foil different festive atmosphere. For example, small drum point is more suitable for solemn and dignified occasions, while round drum point is more suitable for playing and slapstick festive atmosphere. The lyrics of drum and cymbal dance are generally about people, literary quotation, flowers and grass and truth, which show both a deep sense of nostalgia and a love and nostalgia for real life. "... ... In September, leek flower becomes yellow and is beaten by frost. Meng Jiangnv cried down the Great Wall because she missed her husband. In October, cypress flowers fall to the ground, and Han Xiangzi ferried Lin Ying three times with flower basket held in hand. Heavy snow fell in November, and the sky is full of fog. Lv Meng is going to fetch Fanzhai and never return. In December, there are light flowers and every family go up. Emperor Taizu of Song sent Jingiang miles away."[9] Precisely because of the description of historical allusions, myths, and natural features, cymbals and drum folk song and dance reflect transcendence based on man's world and improvement of secular attachment, which is exactly the beauty of Taoism.

\section{CONCLUSION}

To sum up, both the "vulgar beauty" of Confucian and "fairy beauty" of Taoist or the vigorous vitality in northern culture, folk dance in Beijing actually performs the people's love and praise of life, which is a kind of "Live "breath and hope. This is related to the artistic characteristics of the dance and is also influenced by the social environment of Beijing in the 20th century. However, it represents the most 
prominent aesthetic feature of folk dance in Beijing_— the praise for life.

\section{REFERENCES}

[1] Beijing volume editorial department: "Integration of Chinese Folk Dance. Beijing Volume", Chinese ISBN Center, 1992.

[2] Beijing volume editorial department. "Compilation of Folk Dance of Nations in Beijing" (1), Chinese ISBN center, 1987.

[3] Beijing volume editorial department. "Compilation of Folk Dance of Nations in Beijing" (2), Chinese ISBN center, 1989.

[4] Beijing volume editorial department. "Compilation of Folk Dance of Nations in Beijing" (3), Huairou cultural center, 1989.

[5] Zou Hua. Analysis of Origin point of Chinese Aesthetics, Zhonghua Book Company, 2013 